Gut and Liver, Vol. 13, No. 1, January 2019, pp. 48-53

\title{
Impact of Education on School Nurses' Knowledge of Inflammatory Bowel Disease
}

\author{
Eun Soo Kim ${ }^{1}$, Ki Tae Kwon ${ }^{1}$, Sung Kook Kim ${ }^{1}$, Miyoung Kim² ${ }^{2}$, Hyun Seok Lee ${ }^{1}$, Byung IK Jang ${ }^{3}$, Kyeong Ok Kim ${ }^{3}$, \\ Eun Young Kim ${ }^{4}$, Yoo Jin Lee ${ }^{5}$, SuK Jin Hong ${ }^{6}$, Chang Heon Yang ${ }^{7}$, Ben Kang ${ }^{8}$, Byung-Ho Choe ${ }^{8}$, and on behalf of the \\ Crohn's and Colitis Association in Daegu-Gyeongbuk (CCAiD)
}

${ }^{1}$ Department of Internal Medicine, School of Medicine, Kyungpook National University, ${ }^{2}$ Keimyung University College of Nursing; ${ }^{3}$ Department of Internal Medicine, Yeungnam University College of Medicine, ${ }^{4}$ Department of Internal Medicine, Catholic University of Daegu School of Medicine, ${ }^{5}$ Department of Internal Medicine, Keimyung University School of Medicine, ${ }^{6}$ Department of Pediatrics, Catholic University of Daegu School of Medicine, Daegu, ${ }^{7}$ Department of Internal Medicine, Dongguk University School of Medicine, Gyeongju, and ${ }^{8}$ Department of Pediatrics, School of Medicine, Kyungpook National University, Daegu, Korea

Background/Aims: School nurses' knowledge of inflammatory bowel disease (IBD) has not been evaluated. We aimed to investigate school nurses' knowledge of IBD and determine whether education could improve this knowledge. Methods: School nurses were invited to complete self-reported questionnaires on IBD. Then, IBD specialists from tertiary referral hospitals provided a 60-minute lecture with educational brochures on two occasions, with a 3-month interval. Within 6 months after the educational interventions, school nurses were asked to complete the same IBD questionnaire via e-mail. Results: Among 101 school nurses who were invited to participate, 54 nurses (53.5\%) who completed two consecutive questionnaires were included in this study (median age, 45 years; range, 25 to 59 years; 100\% female); $11.1 \%$ and $7.4 \%$ of the study participants had no knowledge regarding ulcerative colitis and Crohn's disease, respectively. They had heard of IBD most frequently from doctors (33.3\%), followed by internet sources (25.9\%). After 6 months, the number of nurses who could explain IBD to students with over 30\% confidence increased from 24 (44.5\%) to 42 $(77.8 \%)(p<0.001)$. Most nurses $(81.5 \%)$ reported that the educational intervention was helpful for managing students with abdominal pain or diarrhea. The number of students who received IBD-related welfare services from the Daegu Metropolitan Office of Education doubled when compared with the corresponding number during the prior educational year. Conclusions: There is room for improvement in school nurses' knowledge of IBD. A systematic educational program on IBD should be implemented for these nurses. (Gut Liver

\section{9;13:48-53)}

Key Words: Inflammatory bowel disease; Crohn disease; Colitis, ulcerative; Schools, nursing

\section{INTRODUCTION}

Inflammatory bowel disease (IBD), which includes Crohn's disease (CD) and ulcerative colitis (UC), is characterized by chronic inflammation of the gastrointestinal tract that often requires life-long management. IBD has a relapsing disease course that negatively impacts patients' quality of life. ${ }^{1,2}$ Although no keys to the pathogenesis of this disease have been clearly identified, environmental and genetic factors are known to be involved in the development of IBD. ${ }^{3}$

In approximately one-quarter of IBD cases, the disease develops during childhood or adolescence. ${ }^{4}$ IBD occurrence at this young age has several clinical implications that merit consideration. First, for IBD, onset at a young age is a factor associated with poor prognosis. For CD, young age at diagnosis is associated with a high risk of upper gastrointestinal involvement, extensive disease and a disabling course. ${ }^{5-7}$ For UC, patients diagnosed at a young age are more likely to have extensive disease, undergo colectomy, and exhibit proximal disease extension and/or colorectal neoplasia. ${ }^{8-10}$ Second, when children do not receive optimal treatment, IBD may cause irreversible linear growth impairment, one of the critical complications of this disease. ${ }^{11}$ Third, for $\mathrm{CD}$, younger age at diagnosis is an independent risk factor for long diagnostic delay, which has a detrimental

Correspondence to: Byung-Ho Choe

Department of Pediatrics, School of Medicine, Kyungpook National University, 680 Gukchaebosang-ro, Jung-gu, Daegu 41944, Korea

Tel: +82-53-200-5704, Fax: +82-53-425-6683, E-mail: bhchoe@knu.ac.kr

Received on March 20, 2018. Revised on May 29, 2018. Accepted on June 17, 2018. Published online November 12,2018

pISSN 1976-2283 eISSN 2005-1212 https://doi.org/10.5009/gnl18139

Eun Soo Kim and Ki Tae Kwon contributed equally to this work as first authors.

@) This is an Open Access article distributed under the terms of the Creative Commons Attribution Non-Commercial License (http://creativecommons.org/licenses/by-nc/4.0) which permits unrestricted non-commercial use, distribution, and reproduction in any medium, provided the original work is properly cited. 
impact on clinical outcomes, leading to issues such as a high risk of intestinal surgery and poor quality of life. ${ }^{12,13}$ Therefore, timely, appropriate management enabled by the early detection of IBD is of utmost importance for young patients with IBD.

Children spend a large proportion of their time at school. According to an Organization for Economic Co-operation and Development (OECD) indicator, for elementary- and middleschool-aged students from OECD countries, the average compulsory instruction times at school are 794 and 905 hours per year, respectively. ${ }^{14}$ These statistics only reflect part of the total time that students are at school because compulsory hours only account for time in formal classroom settings. Therefore, children and adolescents with IBD may experience symptoms while they are at school.

In this context, school nurses who take care of students' health at school may play a crucial role in identifying and managing students with IBD. However, school nurses' knowledge of IBD has never previously been evaluated. Thus, we aimed to assess school nurses' degree of awareness regarding IBD and to determine whether education improved this awareness.

\section{MATERIALS AND METHODS}

\section{Methods}

This investigation was a prospective follow-up study based on a survey that assessed school nurses' knowledge of IBD. School nurses who were registered at the Daegu Metropolitan Office of Education were invited to come to a meeting and asked to complete a questionnaire on IBD. The main questions used in the study were as follows: (1) Have you heard of CD or UC? (2) What is your source of information regarding these conditions? (3) How would you rate your confidence regarding knowledge of IBD in terms of explaining IBD to students? (4) How would you rate your confidence regarding knowledge of IBD in terms of identifying symptoms suspicious for IBD? (5) Do you know of the welfare service system of the Daegu Metropolitan Office of Education for students with IBD?

Since January 2009, the Daegu Metropolitan Office of Education has provided students with IBD with financial support to cover their medical expenses. Candidates for this support have been selected by a school nurse and a homeroom teacher from each school after a review of medical documentation.

After the aforementioned survey was administered, 60-minute educational lectures with brochures regarding the epidemiology, pathogenesis, clinical symptoms, signs, diagnosis, and treatment of IBD were delivered in February 2015 by gastroenterologists from tertiary referral hospitals on two occasions, with a 3-month interval between these occasions. The follow-up survey sent via e-mail was collected within 6 months after the final educational lecture.

\section{Statistical analysis}

Categorical variables were expressed using numbers and percentages, whereas continuous variables were described using median values and ranges. Variables were compared before and after education using paired t-tests. For a question with a dichotomized answer (yes or no), responses before and after education were compared using the McNemar test. All tests were two-sided, and $\mathrm{p}<0.05$ was regarded as indicative of statistical significance. All statistical analyses were performed using SPSS software version 18.0 (SPSS Inc., Chicago, IL, USA).

\section{RESULTS}

\section{Baseline characteristics of school nurses}

Among 101 school nurses invited to participate in the study, 54 respondents (53.5\%) who completed both surveys were eventually included (100\% female; median age, 45 years; range, 2559 years). Their median working experience was 13 years (range, 1-37 years). The median number of students that school nurses were caring for was 688 (range, 100-1,400 students). Twentytwo (40.7\%), 18 (33.3\%) and $14(25.9 \%)$ of the nurses were working at elementary, middle and high schools, respectively. In the nurses' experiences, more students complained of abdominal pain than diarrhea. More than half of the participants (29/54, $53.7 \%$ ) responded that they encountered more than 20 students with abdominal pain per week, whereas only one nurse reported that she encountered more than 20 students with diarrhea per

Table 1. Baseline Characteristics of School Nurses $(n=54)$

\begin{tabular}{lc}
\multicolumn{1}{c}{ Characteristic } & Value \\
\hline Female sex & $54(100)$ \\
Age, yr & $44.4 \pm 8.7$ \\
Working experience, yr & $13(1-37)$ \\
No. of students & $688(100-1,400)$ \\
School & \\
Elementary school & $22(40.7)$ \\
Middle school & $18(33.3)$ \\
High school & $14(25.9)$ \\
No. of students with abdominal pain a week & \\
0 & 0 \\
$1-20$ & $25(46.3)$ \\
$21-40$ & $23(42.6)$ \\
$\geq 41$ & $6(11.1)$ \\
No. of students with diarrhea a week & $5(9.3)$ \\
0 & \\
$1-20$ & $1(1.9)$ \\
$21-40$ & \\
\hline & \\
\hline &
\end{tabular}

Data are presented as number (\%), mean \pm SD, or median (range). 
week. Baseline characteristics of the participants are described in Table 1.

\section{Responses to questionnaires on IBD}

Six (11.1\%) and four (7.4\%) of the school nurses had never heard of UC and CD, respectively (Fig. 1A). For the study participants, information regarding these conditions was most frequently obtained from doctors (46.3\% for UC, 33.3\% for CD), followed by internet searches (27.8\% for UC, 25.9\% for CD) (Fig. 1B).

With respect to confidence regarding knowledge of IBD, the percentage of school nurses who could explain IBD to their students with over 30\% confidence was 44.5\% (24/54). However, this figure significantly increased to $77.8 \%$ (42/54) within 6 months after the educational intervention ( $<<0.001)$ (Fig. 2A). In addition, the percentage of school nurses who replied that they could differentiate students with symptoms suspicious for IBD from those with functional symptoms with over 30\% confidence significantly increased from $11.1 \%$ (6/54) to 27.9\% (15/54) after the educational intervention $(\mathrm{p}<0.001)$ (Fig. 2B).

\section{Awareness of the Daegu Metropolitan Office of Educa- tion's welfare system for students with IBD}

The percentage of school nurses who were aware of the welfare system for students with IBD provided by the Daegu Metropolitan Office of Education also significantly increased from $50 \%(27 / 54)$ to $68.5 \%(37 / 54)$ after the educational intervention (McNemar test $\mathrm{p}=0.038$ ) (Fig. 3A). In addition, the actual
A

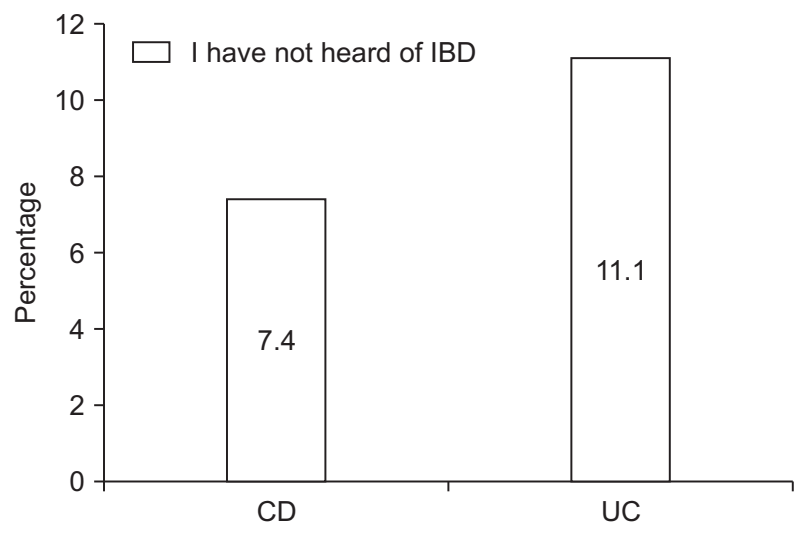

B

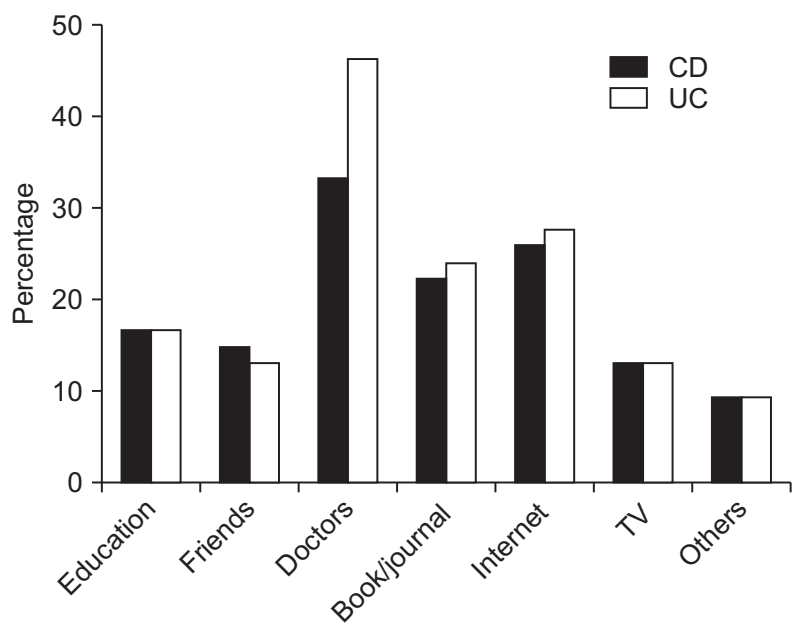

Fig. 1. School nurses' knowledge and sources of information regarding inflammatory bowel disease (IBD). (A) The percentages of school nurses who have not heard of Crohn's disease (CD) or ulcerative colitis (UC). (B) The main sources of information on CD and UC.

A

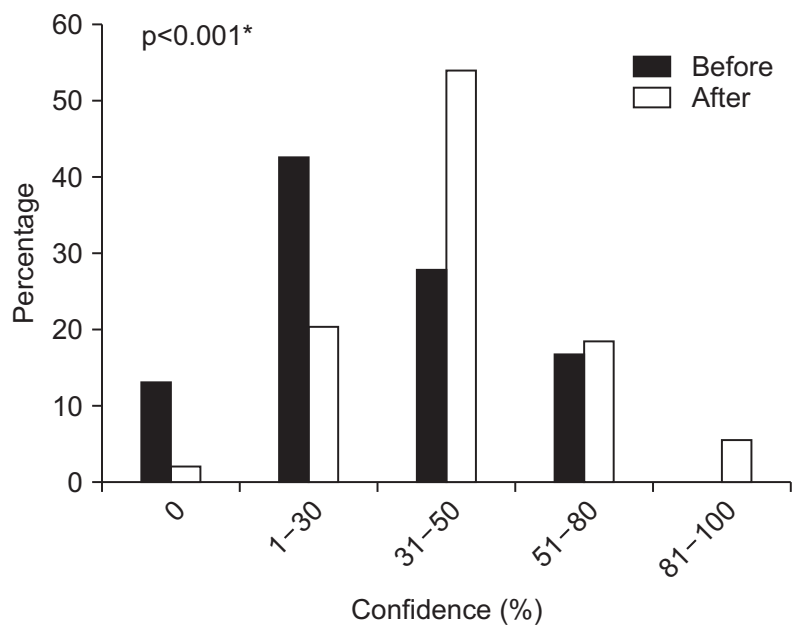

B

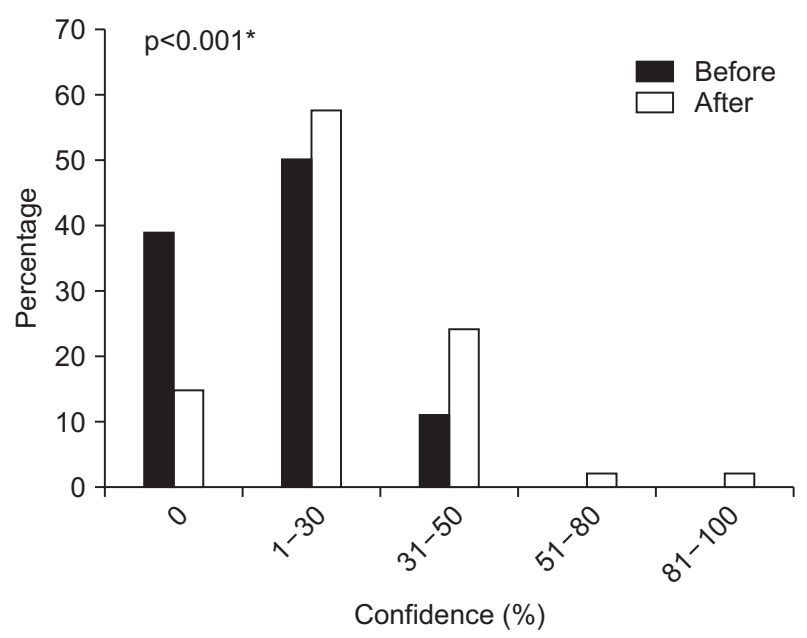

Fig. 2. School nurses' confidence regarding knowledge of inflammatory bowel disease (IBD) before and after education. (A) How would you rate your confidence regarding knowledge of IBD in terms of explaining IBD to students? (B) How would you rate your confidence regarding knowledge of IBD in terms of identifying symptoms suspicious of IBD? *Paired t-test. 
A

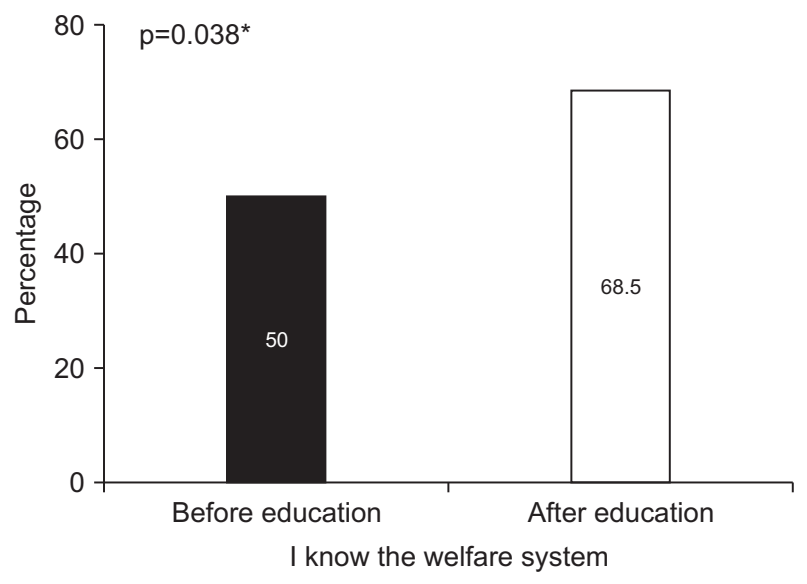

B

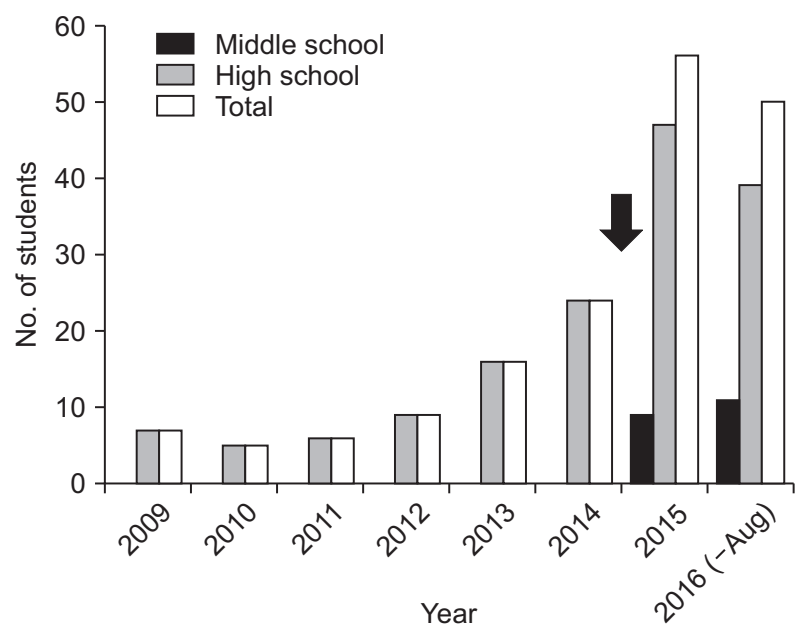

Fig. 3. School nurses' awareness of the welfare service system (A) and the number of students who benefited from this service each year (B). The arrow indicates the educational intervention. *The McNemar test.

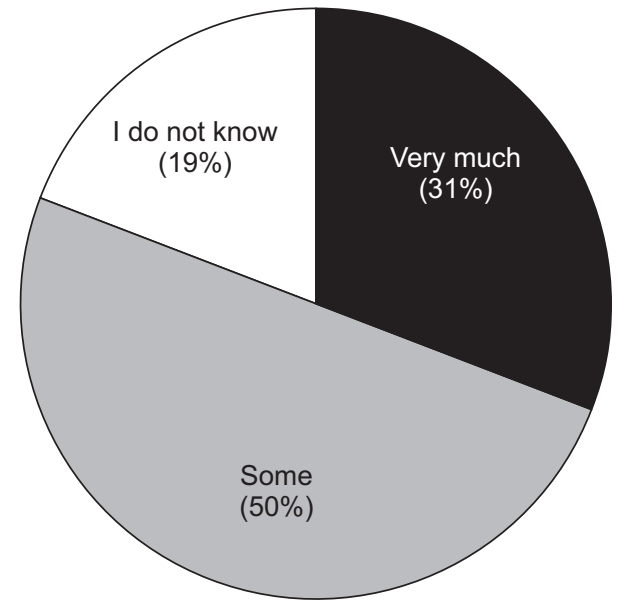

Fig. 4. The percentage of school nurses who responded that the educational intervention was helpful.

number of students with IBD who received this welfare service more than doubled for the year after the educational intervention (arrow, Fig. 3B) compared with the corresponding number for the previous year, increasing from 24 to 56. Notably, the first student with IBD from middle school who benefited from this service was enrolled immediately after the educational intervention (Fig. 3B). Most of the participants (81\%) replied that the educational efforts were helpful for managing students with abdominal pain or diarrhea (Fig. 4).

\section{DISCUSSION}

This follow-up survey-based study showed that one out of ten school nurses did not have any knowledge regarding IBD and that school nurses' overall knowledge did not sufficiently translate to the ability to identify IBD students at schools, sug- gesting suboptimal awareness of IBD in the school nurse population. After medical personnel such as doctors, the internet was school nurses' main source of information regarding IBD. However, educational efforts, in the form of a 60-minute lecture and brochures that were delivered on two occasions with a 3-month interval between occasions, significantly improved school nurses' knowledge of IBD.

The incidence of pediatric IBD has been rapidly increasing in Asian countries, such as South Korea, China and Japan, causing significant social and economic burdens. ${ }^{15-17}$ A recent population-based study of IBD showed that CD incidence was highest (9.1 per $10^{5}$ ) in the age group 15 to 19 years that are middle or high school age. ${ }^{18}$ Further, incidence of pediatric IBD in Daegu area increased from 9 per $10^{5}$ in 2011 to 30 per $10^{5}$ in $2016 .^{19}$ Although the prevalence of IBD remains lower in Asia than in Western countries, it is time to brace for a dramatic surge in Asian patients with IBD.

Given that children and adolescents spend a large portion of time at school, school nurses, who stand on the front lines of medicine at schools, may play an essential role in managing students' various medical conditions. Several studies have evaluated the efficacy of an educational intervention on emergency, disaster or biological event preparedness for school nurses and shown that education significantly improved school nurse preparedness with respect to knowledge and skills. ${ }^{20,21}$ However, no prior studies have determined school nurses' awareness of IBD and assessed the impact of education on this awareness.

Chronic abdominal pain is a major symptom of IBD. ${ }^{22} \mathrm{Al}-$ though most recurrent abdominal pain results from functional disorders such as irritable bowel syndrome, with organic causes (including IBD) only observed in 5\% to $10 \%$ of cases, differentiating among these causes based on symptoms is known to be extremely challenging. ${ }^{23}$ Recurrent abdominal pain is one 
of the most common childhood complaints in general practice, with a prevalence ranging from $10 \%$ to $45 \%$ among schoolgoing children. ${ }^{24}$ In the present study, over half of school nurses (53.7\%) reported that they encountered more than 20 students with abdominal pain per week (Table 1). Therefore, it is integral to have school nurses remain prepared to appropriately manage students with abdominal pain.

The present study showed that among school nurses, the internet was the second most common source of information regarding $\mathrm{IBD}$, after doctors (Fig. 1B). However, the quality of websites with information on IBD greatly varies, suggesting that online material might not be an adequate source of information on IBD. ${ }^{25,26}$ Thus, formal education regarding IBD needs to be provided to school nurses.

It might be a challenge to have a chance to give an educational lecture for a large number of school nurses. There were several steps for us to complete this educational work. Firstly, we contacted the head of school nurses association in Daegu Metropolitan Office of Education and discussed IBD educational program for school nurses. Then, we had a permission to have an educational lecture in the general meeting of school nurses association which was held 1 to 2 times a year. The content of educational lecture was described in Supplementary Table 1.

We found that a 1-hour education session provided twice within a 3-month interval significantly improved school nurses' knowledge of IBD and that the efficacy of the educational intervention persisted for at least 6 months. Although we could not obtain information regarding how many students with IBD were newly identified by school nurses before and after the educational intervention, data that might truly indicate the efficacy of this intervention, we were able to assess the increase in the number of students who received financial support via the welfare services provided by the Daegu Metropolitan Office of Education. Surprisingly, the total number of students more than doubled after the educational intervention, and middle school students with IBD first started to benefit from these services after the intervention. Of course, this study did not address all the pediatric IBD cases in the examined region. However, we assumed that the study data indirectly reflected both the engagement of school nurses regarding the welfare service system in Daegu and the effects of the educational intervention. Taken together, these results show that education is effective for enhancing school nurses' knowledge and preparedness regarding IBD at school.

The small number of participants (54 from 101 school nurses, $53.5 \%$ ) was the main limitation of the study. Also, the result might not be representative because this study was conducted in Daegu area. Therefore, nationwide study with a large number of school nurses is warranted.

In conclusion, there is room for improvement in school nurses' knowledge of IBD. School nurses play a significant role as important liaisons that can collaborate with physicians, fac- ulty and parents regarding student health problems. Therefore, a systematic educational program on IBD should be implemented for these nurses.

\section{CONFLICTS OF INTEREST}

No potential conflict of interest relevant to this article was reported.

\section{ACKNOWLEDGEMENTS}

This work was supported by Basic Science Research Program through the National Research Foundation of Korea (NRF) funded by the Ministry of Education (2015R1D1A1A02062168) and a grant of the Korea Health Technology R\&D Project through the Korea Health Industry Development Institute (KHIDI), funded by the Ministry of Health \& Welfare, Republic of Korea (grant number: HI15C0542).

\section{REFERENCES}

1. Cohen RD. The quality of life in patients with Crohn's disease. Aliment Pharmacol Ther 2002;16:1603-1609.

2. Kim ES, Cho KB, Park KS, et al. Predictive factors of impaired quality of life in Korean patients with inactive inflammatory bowel disease: association with functional gastrointestinal disorders and mood disorders. J Clin Gastroenterol 2013;47:e38-e44.

3. Podolsky DK. Inflammatory bowel disease (1). N Engl J Med 1991; 325:928-937.

4. Kelsen J, Baldassano RN. Inflammatory bowel disease: the difference between children and adults. Inflamm Bowel Dis 2008;14 Suppl 2:S9-S11.

5. Van Limbergen J, Russell RK, Drummond HE, et al Definition of phenotypic characteristics of childhood-onset inflammatory bowel disease. Gastroenterology 2008;135:1114-1122.

6. Beaugerie L, Seksik P, Nion-Larmurier I, Gendre JP, Cosnes J. Predictors of Crohn's disease. Gastroenterology 2006;130:650-656.

7. Charpentier C, Salleron J, Savoye G, et al. Natural history of elderly-onset inflammatory bowel disease: a population-based cohort study. Gut 2014;63:423-432.

8. Falcone RA Jr, Lewis LG, Warner BW. Predicting the need for colectomy in pediatric patients with ulcerative colitis. J Gastrointest Surg 2000;4:201-206.

9. Jess T, Simonsen J, Jørgensen KT, Pedersen BV, Nielsen NM, Frisch M. Decreasing risk of colorectal cancer in patients with inflammatory bowel disease over 30 years. Gastroenterology 2012; 143:375-381.e1.

10. Gower-Rousseau C, Dauchet L, Vernier-Massouille G, et al. The natural history of pediatric ulcerative colitis: a population-based cohort study. Am J Gastroenterol 2009;104:2080-2088.

11. Vasseur F, Gower-Rousseau C, Vernier-Massouille G, et al. Nutritional status and growth in pediatric Crohn's disease: a popula- 
tion-based study. Am J Gastroenterol 2010;105:1893-1900.

12. Vavricka SR, Spigaglia SM, Rogler G, et al. Systematic evaluation of risk factors for diagnostic delay in inflammatory bowel disease. Inflamm Bowel Dis 2012;18:496-505.

13. Schoepfer AM, Dehlavi MA, Fournier N, et al. Diagnostic delay in Crohn's disease is associated with a complicated disease course and increased operation rate. Am J Gastroenterol 2013;108:17441753.

14. Organization for Economic Co-operation and Development. Indicator D1: how much time do students spend in the classroom? Paris: OECD Publishing, 2014.

15. Kim BJ, Song SM, Kim KM, et al. Characteristics and trends in the incidence of inflammatory bowel disease in Korean children: a single-center experience. Dig Dis Sci 2010;55:1989-1995.

16. Ishige $\mathrm{T}$, Tomomasa $\mathrm{T}$, Hatori R, et al. Temporal trend of pediatric inflammatory bowel disease: analysis of national registry data 2004 to 2013 in Japan. J Pediatr Gastroenterol Nutr 2017;65:e80e82.

17. Wang $\mathrm{XQ}$, Zhang $\mathrm{Y}, \mathrm{Xu} \mathrm{CD}$, et al. Inflammatory bowel disease in Chinese children: a multicenter analysis over a decade from Shanghai. Inflamm Bowel Dis 2013;19:423-428.

18. Jung YS, Han M, Kim WH, Park S, Cheon JH. Incidence and clinical outcomes of inflammatory bowel disease in South Korea, 2011-2014: a nationwide population-based study. Dig Dis Sci 2017;62:2102-2112.
19. Hong SJ, Cho SM, Choe BH, et al. Characteristics and incidence trends for pediatric inflammatory bowel disease in Daegu-Kyungpook Province in Korea: a multi-center study. J Korean Med Sci 2018;33:e132.

20. Elgie R, Sapien R, Fullerton L, Moore B. School nurse online emergency preparedness training: an analysis of knowledge, skills, and confidence. J Sch Nurs 2010;26:368-376.

21. Rebmann T, Elliott MB, Artman D, VanNatta M, Wakefield M. Impact of an education intervention on Missouri K-12 school disaster and biological event preparedness. J Sch Health 2016;86:794-802.

22. Siegel CA, MacDermott RP. Is chronic pain an extraintestinal manifestation of IBD? Inflamm Bowel Dis 2009;15:769-771.

23. Weydert JA, Ball TM, Davis MF. Systematic review of treatments for recurrent abdominal pain. Pediatrics 2003;111:e1-e11.

24. Plunkett A, Beattie RM. Recurrent abdominal pain in childhood. J R Soc Med 2005;98:101-106.

25. Bernard A, Langille M, Hughes S, Rose C, Leddin D, Veldhuyzen van Zanten S. A systematic review of patient inflammatory bowel disease information resources on the World Wide Web. Am J Gastroenterol 2007;102:2070-2077.

26. Langille M, Bernard A, Rodgers C, Hughes S, Leddin D, van Zanten SV. Systematic review of the quality of patient information on the internet regarding inflammatory bowel disease treatments. Clin Gastroenterol Hepatol 2010;8:322-328. 